\title{
INKULTURASI DOLO-DOLO SEBAGAI KESENIAN SEKULER KE DALAM LITURGI GEREJA KATOLIK
}

Maria Klara Amarilis Citra Sinta Dewi Tukan. Received: 2 Agustus 2021; Accepted: 20 Agustus 2021; Published: 28 September 2021 Ed. $2021 ; 5$ (1): 16 - 24

\begin{abstract}
Inculturation is a process of absorbing and involving positive elements from local cultures into the Catholic Church as a form of proclamation to God. This research is a qualitative research that aims to describe the practice of inculturating Dolo-Dolo as a secular art into the liturgy of the Catholic Church. The phenomenon of Dolo-dolo art, which is a secular art, used as sacred music through inculturation practices, turns out to be very much based on the background and perspective of the people who influence the practice. This study seeks to understand concretely the factors that underlie and influence Dolo-dolo art which is a secular art which can actually be used as religious worship music in the form of the Dolo-dolo Mass by revealing the factors that have influenced it other than due to an inculturation with using Bourdieu's theory of cultural arena which is positioned as the main theory to answer the two research problem formulations assisted by theory through the discipline of musicology by looking at the musical elements which are elements of Dolo-dolo's identity as a secular art. This research was conducted in the social domain using qualitative data analysis methods and descriptive and interpretive data analysis techniques. The results obtained by this study are a form of understanding the object through a subject with an effort to see and understand the factors that have an important role in the practice of inculturation in a Catholic Church which includes the social space of the Church's people by utilizing the capital of a culture.
\end{abstract}

Keywords: Inculturation, Secular Arts, Dolo-dolo Mass.

\section{PENDAHULUAN}

Karya seni merupakan salah satu produk budaya sebagai ungkapan perasaan manusia yang dituangkan dalam berbagai cabang seni seperti musik, tari, sastra, dan sebagainya. Menurut Dickie (Rondhi, 2017), suatu karya ciptaan manusia dikatakan sebagai suatu karya seni jika menimbulkan pengalaman estetik bagi pengamatnya. Pengalaman ini tidak hanya muncul dari karya-karya yang memang sengaja diciptakan sebagai suatu karya seni, namun juga pada hal-hal lain yang tanpa sengaja akan memunculkan pengalaman estetik ini bagi para penikmatnya.
Dolo-dolo merupakan sebuah jenis kesenian yang mengandung unsur musik, tari dan sastra yang berasal dari pulau Flores Timur (Lamaholot). Ketiga unsur yang terdapat dalam kesenian tersebut saling memiliki keterkaitan antara satu dengan lainnya, yakni di dalam sebuah musik terkandung unsur tari dan sastra. Dalam hal ini, masyarakat yang melakukan Dolo-dolo secara tidak langsung ikut berperan dalam menuangkan bentuk kebahagiaan mereka melalui serangkaian unsur-unsur seni yang diekspresikan dengan cara bernyanyi dalam bentuk saling berbalas pantun sambil menari bersama. 
Pada sejarahnya, Dolo-dolo awal mulanya dilakukan oleh masyarakat Flores Timur di pasar-pasar tradisional sebagai wujud kekeluargaan dan sosialisasi antar masyarakat. Dolo-dolo merupakan bentuk sebuah kegiatan hiburan yang dapat dilakukan oleh siapa saja, tanpa ada aturan-aturan seperti dalam sebuah bentuk ritual ataupun pertunjukan. Kegiatan hiburan ini dapat dijumpai dalam acara-acara kegembiraan seperti pada pesta. Rasa kebersamaan yang terbangun berdampak pada kentalnya wujud kekeluargaan dan sosialisasi masyarakatnya. Kesenian ini bahkan dapat menjadi ajang mencari jodoh, di mana orang-orang berkumpul, membentuk lingkaran untuk bernyanyi, saling berbalas pantun bersama dan menari.

Dalam perkembangannya, sebagai bentuk respons dari wujud akulturasi yang terdapat pada Dolo-dolo ini, Alm. Matheus Weruin menginkulturasikan dalam bentuk Misa Dolo-dolo pada Gereja Katolik sebagai wujud kreativitasnya. Setelah Konsili Vatikan II, Gereja membuka diri untuk menerima bentuk-bentuk positif kebudayaan masuk ke dalam suatu perayaan yang ditandai dengan inkulturasi. Inkulturasi merupakan satu program yang penting dalam Gereja Katolik di seluruh dunia yakni dengan melibatkan bentuk-bentuk budaya lokal dalam liturgi yang dibangunnya. Melaluinya, Gereja mengakui dan menghormati budaya-budaya seperti yang terjadi pada kesenian Dolo-dolo. Misa Dolo-dolo ini merupakan suatu gaya nyanyian khas Flores Timur yang mana kekhasannya (gaya dolo-dolo) itu tampak melalui unsur musikalnya yakni pada ritmenya. Selain itu unsur-unsur seperti melodi, bahkan unsur-unsur di luar musikalnya seperti bahasa (sastra) dan tari pun ikut menjadi suatu bentuk kesatuan dari karakteristik Dolo-dolo. Keunikannya tersebut terdapat pada motif-motif daerah berupa elemen-elemen pada keseniannya dimana dalam bentuk kebudayaannya menggambarkan makna atau fungsi dari suatu bentuk hiburan yang justru pada akhirnya dapat masuk ke dalam sebuah liturgi Gereja Katolik melalui inkulturasi.
Seperti yang diketahui bahwa dalam sebuah Gereja sudah tentu memiliki peraturan-peraturan yang harus ditaati dan disesuaikan di mana dalam objek penelitian ini lebih dikhususkan pada bagian musik liturgi. Sebelum Konsili Vatikan II, pada musik liturgi mulai dari bentuk musiknya dan bahkan alat musik yang digunakan sangatlah dibatasi sehingga jika dibandingkan dengan sekarang, musik liturgi sudah sangat berkembang walaupun tetap disesuaikan dan tetap berada dalam kaidah-kaidah liturgi sebuah Gereja. Sebenarnya hal umum yang sudah menjadi perspektif umat yaitu sesuatu yang bersifat sakral adalah suasana doa yang terkesan tenang dan syahdu. Namun hal ini menjadi bertentangan ketika dikaitkan dengan bentuk aksen ritme pada gaya Dolo-dolo. Sebagai suatu kesenian sekuler, bentuk aksen pada ritme Dolo-dolo menggambarkan sesuatu yang terkesan jauh dari suasana tenang dan syahdu. Hal ini terlihat dari alat-alat musik yang digunakan dalam perkembangannya tidak jarang menggunakan alat musik seperti Gitar, Kolintang, Biola, Gong, dan Gendang. Alat-alat musik ini biasanya selalu digunakan dalam acara-acara di luar perayaan Gereja Katolik yang mana dalam Gereja Katolik sangat mengutamakan kesakralan dengan melihat perbandingannya dahulu bahwa iringan musik liturgi hanya menggunakan alat musik Organ. Jika dilihat secara umum, alat-alat musik tersebut identik pada perayaan-perayaan yang bersifat sekuler. Adapun dalam pelaksanaannya dalam perayaan liturgi, Misa Dolo-dolo ini digunakan dalam liturgi pada masa biasa yang mana dapat digunakan pada hari minggu biasa di luar masa-masa khusus seperti masa Adventus, masa Natal, masa Prapaskah dan masa Paskah.

Berdasarkan fenomena-fenomena yang telah dipaparkan diatas, peneliti tertarik untuk melakukan penelitian tentang praktik inkulturasi kesenian sekuler dalam Gereja Katolik. Masalah penelitian ini dibatasi pada faktor-faktor yang mendasari dijadikannya bentuk Misa Dolo-dolo yang merupakan sebuah bentuk seni sekuler dalam suatu ranah sakral. 


\section{METODE PENELITIAN}

Penelitian ini menggunakan metode kualitatif dengan pendekatan studi kasus (case study) terhadap Dolo-dolo dalam konteks penggunaan inkulturasi Misa Dolo-dolo pada Gereja Katolik. Metode pengumpulan data dilakukan dengan cara observasi berupa pengamatan langsung mulai dari proses latihan hingga pada saat perayaan Misa berlangsung serta wawancara mendalam dari beberapa narasumber terkait Dolo-dolo.

Pada penelitian ini terdapat dua jenis data yaitu data primer dan data sekunder. Data primer merupakan data yang diperoleh dari hasil observasi berupa pengamatan terhadap perayaan Misa Kudus dalam praktik inkulturasi pada Misa Dolo-dolo, mulai dari proses latihan yang dilakukan oleh anggota koor dan pemain musik, pengamatan terhadap keberlangsungan Misa Kudus, umat, serta dilakukan wawancara mendalam terhadap narasumber utama dan juga umat yang terlibat dengan praktik Misa Dolo-dolo. Pada penelitian ini informan utama yang penulis pilih ialah Stefanus Dominggo da Silva yang merupakan seniman dan praktisi Dolo-dolo, selanjutnya Romo Philipus Pilich sebagai Romo Paroki Gereja yang sangat terlibat dalam perkembangan bentuk praktik inkulturasi dalam Gereja ini, kemudian beberapa informan di lapangan dari anggota koor dan umat yang terlibat dalam penggunaan Misa Dolo-dolo dalam praktiknya pada Misa Kudus di Gereja Katolik St. Simon Petrus Tarus, Kupang. Sedangkan untuk data sekunder diperoleh dari literatur dan dokumen-dokumen.

Teknik pengumpulan data yang dilakukan dalam penelitian ini lebih mengutamakan penggunaan teknik observasi serta melakukan wawancara mendalam terhadap beberapa narasumber utama untuk melihat faktor yang melatarbelakangi kesenian Dolo-dolo sehingga dalam perkembangannya dapat berinkulturasi dalam sebuah arena yang berbeda yakni Gereja Katolik. Alat pengumpul data yang digunakan dalam penelitian ini berupa rekaman audio, video dari para narasumber yang kemudian dibuat dalam bentuk verbatim. Pengumpulan data dilakukan dalam beberapa langkah untuk memenuhi data yang sesuai dengan pertanyaan penelitian, adapun beberapa langkah-langkah tersebut antara lain:

1. Sebelum terjun ke lapangan, terlebih dahulu peneliti melakukan studi kepustakaan untuk mendapatkan informasi mengenai penelitian sebelumnya yang terkait dengan bentuk inkulturasi dari tradisi budaya dan juga dalam bentuk perkembangan pada praktiknya. kegiatan ini bertujuan untuk mempersiapkan dan menyusun konsep-konsep dalam penelitian serta menentukan narasumber yang dapat membantu proses penelitian ini dalam memberikan informasi.

2. Melakukan observasi pada Gereja Katolik St. Simon Petrus Tarus Kupang yang merupakan tempat pelaksanaan praktik inkulturasi Misa Dolo-dolo dalam penelitian ini. Observasi data dalam penelitian ini adalah mengamati dan mengikuti secara langsung selama proses latihan koor dan musik Misa Dolo-dolo. Pengamatan ini berlangsung selama 1,5 bulan dengan jadwal latihan 1 minggu satu kali pertemuan. Hal-hal yang menjadi sasaran peneliti dalam mencari jawaban dari penelitian ini adalah lebih kepada kondisi yang dialami subjek selama melakukan praktik inkulturasi terhadap Misa Dolo-dolo ini sesuai dengan latar belakang dan perkembangan dalam pelaksanaan yang dirasakan. Adapun selama proses pengamatan hingga pada pelaksanaannya berlangsung, peneliti mengambil beberapa data berupa dokumentasi video, foto, dan juga melakukan wawancara terhadap beberapa umat yang bersifat sebagai tambahan informasi.

3. Melakukan wawancara secara mendalam dengan tujuan mengumpulkan informasi yang kompleks, yang mana sebagian besar berisi pendapat, pengala- 
man dan sikap. Alat bantu yang peneliti gunakan adalah berupa perekam suara dan juga catatan-catatan yang ditulis peneliti. Wawancara ini dilakukan secara mendalam terhadap 2 orang narasumber yaitu seorang seniman yakni Stefanus Dominggo da Silva dan juga seorang Romo sebagai pastor paroki di Gereja tempat penelitian yakni Romo Philipus Pilich dengan membahas mengenai objek penelitian yang berisi informasi-informasi berupa latar belakang, perkembangan dan pelaksanaan praktik inkulturasi Misa Dolo-dolo.

Setelah mendapatkan data-data melalui proses yang dilakukan dengan beberapa tahapan dalam pengumpulan data, peneliti akan melakukan penyederhanaan terhadap hasil catatan lapangan, wawancara, dan dokumentasi audio visual. Sejumlah data yang telah didapatkan akan direduksi yang mana pada tahap ini peneliti berusaha untuk melakukan pemilahan data yang dianggap penting dan akurat baik dari data primer maupun sekunder dalam satuan konsep-konsep, kategori-kategori, dengan tema penelitian dan akan diolah secara analisis deskriptif. Untuk membantu mendapatkan ketajaman analisis, digunakan teori utama yakni teori arena kultural Bourdieu dengan teori konsep musikologi sebagai pendukung.

\section{HASIL DAN PEMBAHASAN}

Inkulturasi di Gereja Katolik Gereja adalah setiap kelompok orang yang sudah mengimani dan percaya kepada Yesus. Pada Konsili Vatikan II, Gereja Katolik mulai memandang positif suatu kebudayaan. Gereja Katolik mulai muncul dengan gagasan-gagasan berdasarkan nilai-nilai sosial budaya masyarakat tradisional dalam upacara-upacara Gereja. Istilah inkulturasi (inculturation) berasal dari lingkungan teologi misi. Istilah ini mulai berkembang sesudah Konsili Vatikan II yang dipopulerkan oleh Joseph Mason pada tahun 1959 dalam teologi misi. Istilah inkulturasi dipakai pertama kali dalam dokumen resmi Gereja tahun 1977, yaitu oleh sinode para uskup di Roma mengenai katekese (pelajaran agama), yang mengeluarkan naskah: "pesan kepada umat Allah". Dikatakan bahwa warta atau pesan Kristiani mesti berakar dalam kebudayaan-kebudayaan dan untuk itu menyampaikan pesan tidak hanya lewat "memberi kepada" melainkan "menerima dari" kebudayaan-kebudayaan yang mendengarkan injil.

Berdasarkan pengamatan yang dilakukan selama proses penelitian, ditemukan bentuk-bentuk positif yang begitu terasa melalui bentuk kesenian sekuler ini dalam bentuk praktiknya yakni Misa Dolo-dolo pada umat berupa adanya bawaan sikap dan pandangan mereka saat mempraktikkannya. Pandangan tersebut berupa hal-hal yang berasal dari bentuk kebiasaan yang mereka lakukan terhadap kesenian Dolo-dolo yang mana rasa kegembiraanlah yang tertanam pada diri mereka. Selain itu juga, adanya perpaduan dari unsur kekuasaan Gereja yang mana sangat mempengaruhi pandangan dan sikap dari umat saat mempraktikkannya, sehingga melalui perpaduan perspektif dari umat tersebut sangat berpengaruh pada hasil yakni Dolo-dolo memang pantas digunakan sebagai musik ibadat religius. Secara detail yang terlihat pada umat paroki adalah berupa sikap semangat yang tinggi saat menyanyikannya yang tergambarkan pada dinamik lagu yang terkadang tidak dapat dikontrol dengan baik, kemudian pesan dari syair (doa) menjadi lebih bermakna yang terlihat jelas dari kekhusyukan pada keseluruhan rangkaian perayaan Misa. Hal-hal tersebut juga sesuai dengan apa yang dirasakan Romo Philipus melalui pengalamannya dalam menanggapi pelaksanaan inkulturasi Misa Dolo-dolo yang dilaksanakan di paroki ini yang mana respons umat paroki tersebut sangat berpengaruh terhadap praktiknya dalam perayaan liturgi yang mana hal tersebut terlihat melalui suasana sakral saat Misa Kudus berlangsung di Gereja Katolik St. Simon Petrus Tarus Kupang. Pada hakikatnya, Gereja merupakan tempat persekutuan umat kepada Tuhan, yang mempunyai hubungan dengan Tuhan dan juga merupakan sebuah wadah persekutuan 
sosial antar umat, yaitu persekutuan antara orang percaya dari segala arah. Dalam hubungan-hubungan ini, terdapat nilai-nilai lain yang diikutsertakan yang mana tidak bisa lepas dari konteks budaya sebagai salah satu bentuk realitas sosialnya. Seperti halnya dalam perkembangannya secara praktik di Gereja St. Simon Petrus ini yang dalam pelaksanaannya selalu memasukkan unsur-unsur budaya di dalamnya seperti bentuk inkulturasi musik liturgi yakni Misa Dolo-dolo dan juga bentuk lainnya seperti penggunaan tarian daerah dalam Misa Kudus dan penggunaan atributatribut Gereja yang bercorak etnik daerah. Dalam proses tersebut, umat yang sejak awal dibentuk dalam lingkungan kebudayaannya, mengikuti adat-istiadat dan menghargai setiap nilai budaya yang telah ditetapkan agar menjadi bagian dari budaya itu, maka proses inkulturasi dalam suatu budaya dapat dikatakan sebagai suatu bentuk proses sosialisasi yang benar-benar dilakukan oleh umat paroki ini melalui praktik inkulturasi Misa Dolo-dolo.

Faktor-faktor yang harus diperhatikan oleh umat dalam menyanyikan gaya Misa Dolo-dolo ini adalah melalui unsur-unsur musikalnya yang mana disini "ritme" menjadi bentuk dasar identitas Dolo-dolo, selanjutnya hubungan dari alur dan suasana yang didapatkan dari unsur tari dan sastra yang notabene harus dihayati dan dipahami terlebih dahulu melalui rasa musikalitas tiap individu. Melalui faktor-faktor tersebut, masyarakat mengeksporasikan kreativitas mereka berdasarkan bentuk kebiasaan dalam suatu kebudayaan yang luhur nilainya di mana menjadi suatu bentuk identitas dari Dolo-dolo, yang masuk dan disesuaikan dalam sebuah liturgi Gereja Katolik.

Berdasarkan pengamatan dari peneliti, bentuk ritme yang mencirikan dan memberi gambaran suasana Dolo-dolo sebagai kesenian sekuler yang bertolak belakang dengan sesuatu yang sakral, justru dalam praktiknya pada Misa Dolo-dolo ini terlihat menghidupkan suasana doa yang tetap berada dalam kesakralannya. Hal tersebut terjadi karena adanya keterkaitan hubungan dari unsur-unsur lainnya, seperti unsur sastra yakni pada syair di mana menggunakan isi Kitab Suci yang disesuaikan dengan tema pada bagian liturgi tersebut. Kaidahkaidah dalam Gereja tersebut, dimaksudkan agar produk budaya yang diinkulturasikan tetap dalam tujuan dan makna inkulturasi pada Misa Kudus. Selain itu, seorang seniman Dolo-dolo, yaitu bapak Stefanus da Silva dalam wawancara mengungkapkan pengalamannya selama mengikuti praktik Misa Dolo-dolo bahwa ia mendapatkan nuansa yang sangat positif dalam memaknai iman melalui setiap unsur pada motif budaya ini. Dolo-dolo dengan unsur-unsur yang terkandung didalamnya sudah menjadi identitas dari masyarakat dalam kesehariannya sehingga secara tidak langsung umat dapat lebih mudah memaknai maksud dan tujuan liturgi tersebut. Selain hasil wawancara mendalam dan pengamatan langsung, juga dibuktikan berdasarkan angket yang ditujukan pada subjek bahwa pengaruh dari unsur-unsur seni seperti musik, tari, sastra yang terdapat dalam Dolo-dolo ini memang sangat kuat dan mampu membentuk rasa dan kondisi umat dari segi sosial yang berpengaruh pada praktiknya.

\section{Misa Dolo-dolo}

Tradisi musik merupakan khazanah Gereja universal yang tak terduga nilainya. Musik yang masuk dalam Gereja tentu saja harus mengikuti kaidah-kaidah yang merupakan tujuan musik suci. Adapun hal yang dimaksud adalah musik atau lagu-lagu yang digunakan tersebut harus sesuai dengan tema perayaan Misa atau ibadat dengan memperhatikan hubungan antara faktor-faktor dengan konsep maupun konteksnya. Karenanya, Gereja Katolik senantiasa melakukan reformasi yang sesuai dengan keadaan dan perkembangan yang ada, termasuk juga dalam bentuk musik liturginya dengan kreativitas-kreativitas dalam praktiknya melalui kebudayaan.

Melalui wawancara Bapak Stefanus da Silva, mengatakan bahwa saat ini Gereja-gereja di NTT khususnya di Flores Timur (Larantuka) yang merupakan daerah asal dari keseni- 
an Dolo-dolo, selalu menggunakan berbagai macam instrumen untuk mengiringi nyanyian pada Misa Dolo-dolo dengan tujuan agar lebih memunculkan gairah dalam liturgi untuk menghindari sesuatu yang monoton. Nuansa pada Misa Dolo-dolo selalu mempunyai kesan tersendiri bagi umatnya. Hal tersebut didasari oleh adanya hubungan dari unsur-unsur musikal pada objek itu sendiri dan juga unsur sosial yang menjadi parameter penting dalam sebuah inkulturasi. Berdasarkan pengamatan disimpulkan bahwa perpaduan antara intra musikal dan juga ekstra musikal berupa syairnya merupakan faktor yang paling mempengaruhi keberhasilan makna dan tujuan, dalam hal ini Dolo-dolo memang layak digunakan sebagai musik ibadat religius. Faktor-faktor tersebut merupakan sebuah modal harus disesuaikan dengan arena dan juga habitus dalam penggunaannya. Dalam praktiknya pada Gereja ini, Romo Philipus mengatakan bahwa belum adanya keseimbangan dari umat sehingga terkadang semangat yang nampak pada umat tersebut belum diimbangi dengan pemahaman terhadap konsep maupun konteks yang sangat berpengaruh pada praktiknya. Adapun butuh waktu yang cukup panjang bagi subjek untuk berlatih agar dapat menyanyikan Misa Dolo-dolo ini sesuai dengan hakikat dari kebudayaan ini.

Misa merupakan sebuah perayaan liturgi Ekaristi. Pada umumnya dikenal dua jenis nyanyian dalam Misa yakni nyanyian ordinarium dan proprium. Dalam penelitian ini, peneliti hanya memfokuskan pada bagian ordinarium. Ordinarium merupakan bagian perayaan Ekaristi yang selalu sama atau tetap, yang mana pada bagian-bagiannya tersebut tidak dapat ditambah atau dikurangi karena sudah berdasarkan aturan-aturan yang telah dirumuskan dan ditetapkan dalam sebuah liturgi. Ordinarium meliputi Kyrie (Tuhan kasihanilah), Gloria (Kemuliaan), Credo (Aku Percaya), Sanctus (Kudus), Pater Noster (Bapa Kami), dan Agnus dei (Anak domba Allah).

Dalam nyanyian ordinarium Misa Dolo-dolo ini, Alm. Matheus Weruin menciptakan bentuk inkulturasinya hanya pada empat bagian saja yakni Kyrie, Gloria, Sanctus, dan Agnus Dei. Beliau merupakan seorang guru musik yang cukup terkenal di seluruh Flores Timur. Bermula dari rasa kebanggaannya atas diangkatnya uskup baru Mgr. Darius Nggawa SVD pada tahun 1974, Alm. Matheus Weruin pun terdorong untuk membuat karyanya dalam bentuk Misa dengan mengolah bagian-bagian lagu setempat (lagu Dolo-dolo) sehingga terciptalah bentuk inkulturasi dalam bentuk Misa Dolo-dolo. Melalui motif ritme dan melodi yang terdapat pada Dolo-dolo asli tersebut, yakni dari lagu daerah "Angin dai", "Doang kae" dan juga lagu yang digunakan dalam berdolo-dolo yakni " Tega cinta nona manis " seperti yang telah ditampilkan sebelumnya ini menjadi inspirasi Alm. Matheus Weruin dalam menciptakan Misa Dolo-dolo. Berikut ini merupakan bentuk teks nyanyian ordinarium "Misa Dolo-dolo" yang terdapat dalam buku nyanyian Madah Bakti sebagaimana dinyanyikan dalam Gereja Katolik.

\section{Kyrie (Tuban Kasihanilab)}

Bagian ini merupakan suatu bentuk seruan mohon belas kasihan dari Allah yang mana merupakan ungkapan lanjutan dari pernyataan tobat untuk memohon belas kasihanNya. Dalam praktiknya di Gereja Katolik Paroki St. Simon Petrus Tarus Kupang, terlihat melalui penghayatan tulus dari hampir sebagian besar umat saat menyanyikannya. Hal ini didapatkan melalui hasil paduan dari unsur-unsur musikal yang terdapat didalamnya. Dalam hal ini, ritme Dolo-dolo menjadi pemegang kendali yang kuat dalam menunjukkan kekhasan motif etnik tersebut, disamping adanya jalinan melodi-melodi yang membentuk sebuah harmonisasi. Melodi-melodi dalam nyanyian "Tuhan Kasihanilah" ini mengambil persis melodi pada lagu daerah "Angin dai" yang kemudian pada bagian solo nya dikembangkan dalam bentuk variasi melodi yang tentu saja tidak lepas dari bentuk aslinya. Pada hakikatnya, Dolo-dolo yang bersifat gembira ini tidak berarti hanya dapat digunakan untuk berse- 
nang-senang seperti halnya yang biasa digunakan dalam kedudukannya yakni sebagai hiburan. Dalam keadaan ini, unsur-unsur seperti melodi, syair dan tempo disesuaikan dengan tema liturgi sehingga apa yang menjadi makna pada bagian liturgi tersebut dapat tersampaikan dengan baik dalam penghayatan iman.

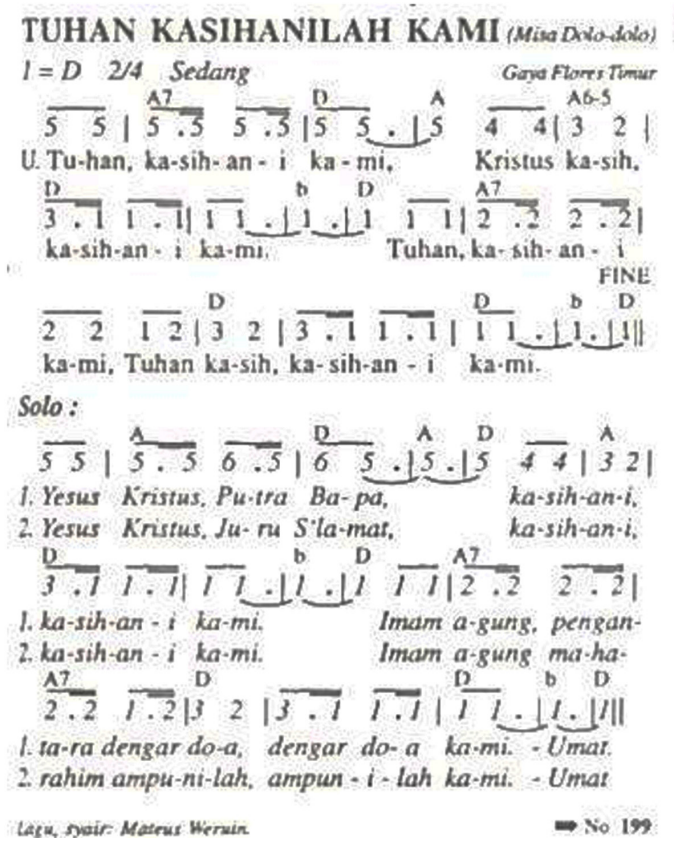

Gambar 1. Lagu Tuhan Kasihailah Kami

\section{Gloria (Kemuliaan)}

Merupakan madah pujian meriah kepada Allah Bapa yang menurunkan rahmat dan berkat, kemuliaan dan kedamaian bagi manusia yang dicintaiNya. Pada bentuk lagu kemuliaan Misa Dolo-dolo di sini, motif ritme menjadi suatu unsur musikal yang kuat dalam menciptakan suasana etnik Flores Timur yakni gaya Dolo-dolo. Untuk ritmenya, selain alat musik bongo (kendang) yang memegang kendali, juga pada organ dan gitar. Sementara itu, biola memainkan melodi yang tetap berada dalam atmosfir ritme etnik. Dalam artian bahwa, melodi dimainkan dengan aksen etnik daerah tersebut (Dolo-dolo). Dengan demikian, unsur ritme benar-benar menjadi unsur paling dominan yang menonjolkan kekhasan gaya Dolo-dolo khusus dalam bentuk Misa Dolo-dolo. Iringan dengan menggunakan berbagai instrumen disini sebagai bentuk pengembangan dalam sebuah inkulturasi dengan tujuan agar nyanyian tersebut dapat lebih mudah dihayati dalam memaknai pujian kepada Tuhan.

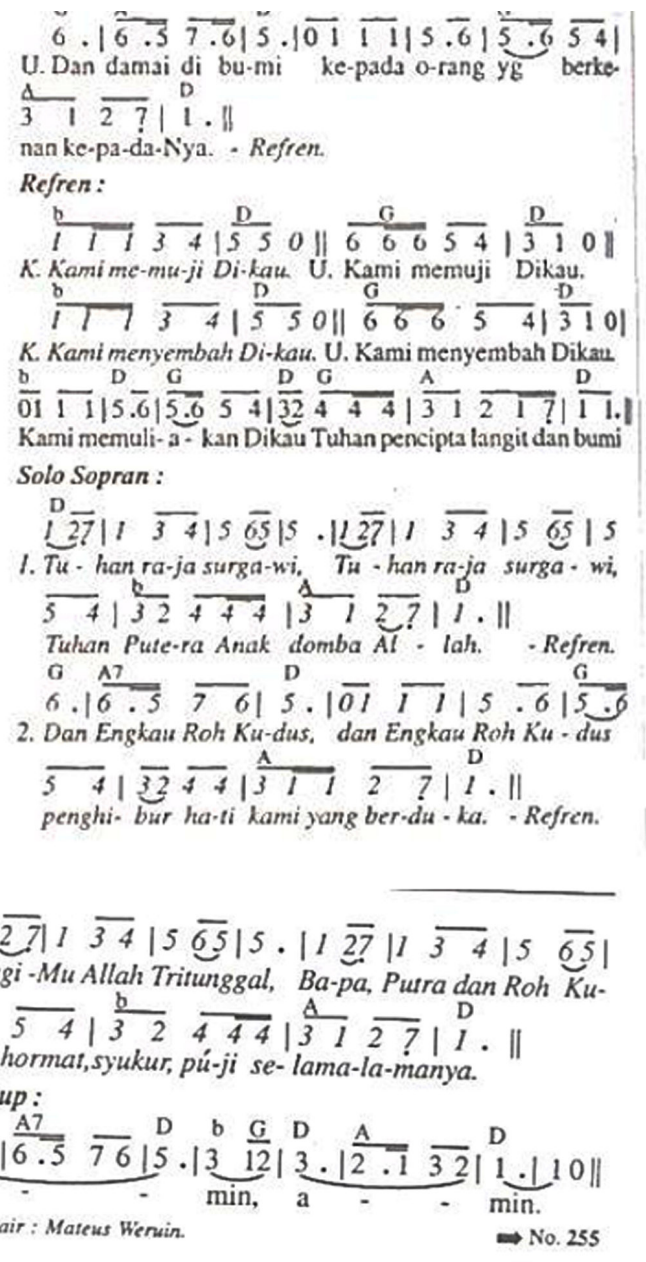

Gambar 2. Lagu Kemuliaan.

\section{Sanctus (Kudus)}

Peran Sanctus (kudus) adalah mengajak seluruh umat beriman untuk masuk dan bersatu dalam Doa Syukur Agung. Fungsi Sanctus adalah doa syukur seluruh umat kepada Tuhan agar seluruh umat beriman mempersatukan diri dengan Kristus dalam memuji karya Allah yang agung dan dalam mempersembahkan kurban. Sanctus ditempatkan setelah prefasi dan sebelum Doa Ekaristi. Dengan demikian, Sanctus (kudus) menjadi bagian integral dari keseluruhan Doa Syukur Agung sebagai wujud dalam menghormati kekudusan dan kesucian Kristus. Tidak berbeda dengan bagian-bagian lainnya, di sini unsur ritme dan melodi diciptakan sesuai dengan makna dan tujuan dari tema, 
semuanya telah diperhitungkan tergantung bagaimana kita sebagai umat memaknainya. Bentuk melodinya merupakan bagian dari lagu "Angin dai" yang telah divariasikan.

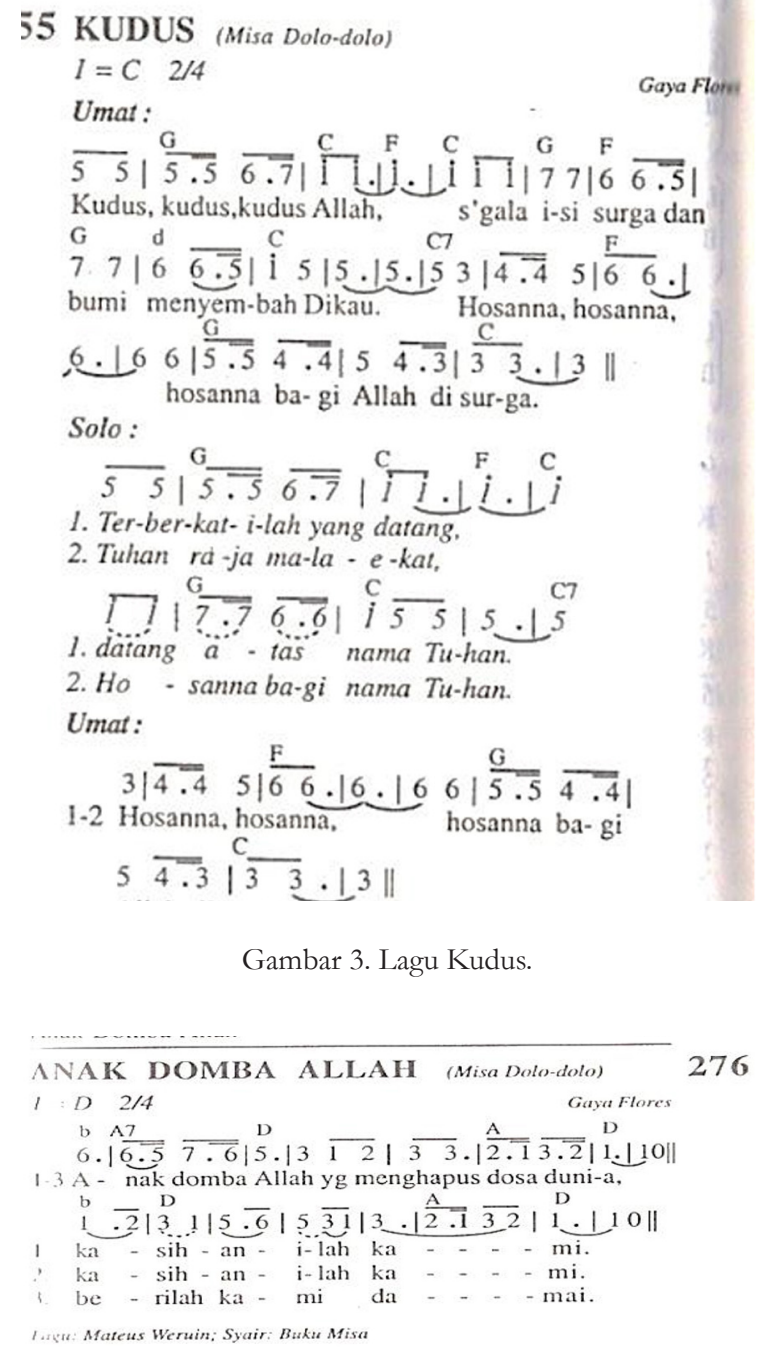

Gambar 4. Anak Domba Allah

\section{KESIMPULAN}

Kesenian Dolo-dolo yang dikenal dengan identitasnya sebagai sebuah kesenian sekuler yang selalu digunakan sebagai hiburan di dalam acara-acara kegembiraan, digunakan juga dalam Gereja Katolik dalam bentuk nyanyian Misa Dolo-dolo sebagai bentuk musik liturgi (musik ibadat religius). Berdasarkan hasil penelitian ditemukan bahwa dari segi musikalnya, Misa Dolo-Dolo banyak memuat perpaduan antara unsur ritme dan melodi yang kemudian dipadukan dengan unsur sastra berupa syair lagu untuk menghasilkan makna dari sebuah perayaan Misa Kudus. Sementara dari faktor sosialnya, terdapat pada perilaku umat saat mempraktikkannya yang tampak antusias saat mengikuti Misa Dolo-dolo ini.

\section{DAFTAR PUSTAKA}

Bourdieu, Pierre.

2010. Arena Produksi Kultural, Sebuah Kajian Sosiologi Budaya. Yogyakarta:

Kreasi Wacana.

HADI, Y, S.

2006. Seni dalam Ritual Agama. Yogyakarta: Pustaka

TAKWIN, B.

2009. (Habitus $\times$ Modal) $=$ Praktik "Pengantar Paling Komprehensif Kepada Pemikiran Pierre Bourdieu”. Yogyakarta: Jala Sutra.

Martasudjita, E \& Kristanto, J. 2007. Panduan Memilih Nyanyian Liturgi. Yogyakarta: Kanisius.

Moleong, J, L.

2007. Metodologi Penelitian Kualitatif.

Bandung: Pt. Remaja Rosdakarya.

Prier, E, K.

2014. Inkulturasi Muik Liturgi I.

Yogyakarta: Pusat Musik Liturgi.

2014. Inkulturasi Muik Liturgi II. Yogyakarta: Pusat Musik Liturgi.

2015. Panduan Musik Liturgi. Yogyakarta: Pusat Musik Liturgi.

Pusat Musik Liturgi.

2007. Madah Bakti. Yogyakarta: Pusat Musik Liturgi.

Pattinaja, Maryon Daniaputra.

2011. Kapata Gareja: Kajian Etnomusikologis Terbadap Nyanyian Liturgi Kontekstual 
di Gereja Protestan Maluku. Tesis.

Program Pascasarjana Institut

Seni Indonesia, Yogyakarta.

RIBERU, J.

1983. Tonggak Sejarah Pedoman Arah Doku men Konsili Vatikan II. Jakarta:

Dokpen Mawi.

RondHI, M.

2017. Apresiasi Seni dalam Konteks

Pendidikan Seni. Jurnal Imajinasi. 11(1): 9-17.

Rumengan, P.

2009. Musik Gerejawi Kontekstual Etnik.

Minahasa: Panitia Pelaksana Kongres

Kebudayaan.

Rumengan, Perry.

2003. Misa Opo Empung Renga-rengan. (Tesis).

Yogyakarta: Program Pascasarjana

Institut Seni Indonesia

(Tidak Diterbitkan).

SigoAma, P. A.

1984. Komposisi Lagu Menuju Musik. Liturgi.

Ende: Nusa Indah.

THOHIR, M.

2013. Metodologi Penelitian Sosial Budaya

(Berdasarkan Pendekatan Kualitatif).

Semarang: Fasindo Press.

TAdu.,Riwu, E, J.

2005. Inkulturasi Musik Liturgi Agnus Dei

(Anak Domba Allab)

Anak Domba Allah dinyanyikan atau didaraskan untuk mengiringi upacara pemecahan roti. Menyanyikan atau mendaraskan dapat dilakukan oleh paduan suara ataupun solis, yang kemudian di jawab oleh umat. Seruan Anak Domba Allah ini adalah sebuah bentuk penyampaian pujian umat beriman kepada Kristus yang telah mengurbankan diri-Nya untuk manusia yang kini hadir sebagai Tuhan yang mulia di atas Altar.
Bentuk yang menandakan pujian ini tampak melalui lirik yang kata-katanya disesuaikan dengan makna dalam perayaan liturgi. Dengan suasana musik yang sesuai dengan jalinan ritme dan melodi etnik tersebut, sangat mempengaruhi jiwa lagu yang sesuai dalam pemaknaan dalam memuji dan bersyukur kepada Tuhan. Bentuk melodi pada nyanyian Anak Domba Allah ini berdasarkan lagu daerah Dolo-dolo yang berjudul "Doang kae" dengan variasi pada melodi dan ritmenya.

di Gereja Masehi Injili di Timor. (Tesis). Yogyakarta: Program Pascasarjana Institut Seni Indonesia (Tidak diterbitkan) 